\title{
“A COMPARATIVE STUDY OF EMOTIONAL COMPETENCIES BETWEEN THE PARENTED FEMALE ADOLESCENT AND ORPHANAGE FEMALE ADOLESCENT"
}

\section{Dr. Ashwin Savjibhai Amraniya}

\begin{abstract}
Present study is conducted to compare the Normal and Orphanage adolescent in relation to their emotional competencies.

The total sample of 60 has been taken from orphanage house (Ahmedabad) and female adolescent from normal households. Revised scale of emotional competencies of Dr. H.C.Sharma and Dr. R.L.Bhardwaj was taken for the study. Scoring has been done as per manual, further it has been analyzed by t-test.

The t-test is not found significant on all the competencies between orphanage and normal adolescent. So, the hypothesis "There is no difference in emotional competency of orphanage female adolescent and normal female adolescent" is rightly rejected, which indicates that there is no difference in emotional competencies of orphanage female adolescent and normal female adolescent.
\end{abstract}

Key words : Emotional Competencies, Orphanage, Adequate Depth of Feeling (ADF), Adequate Expression and Control of Emotions (AECE), Ability to Function with Emotions (AFE), Ability to Cope with Problem Emotions (ACPE), Enhancement of Positive Emotions (EPE), Self-awareness, Self-regulation, Motivation, Empathy, awareness of others' feelings, needs and concerns, Social skills, Group working skills.

\section{Problem:}

"A comparative study of emotional competencies between the parented female adolescent and Orphanage female adolescent" 


\section{Introduction:}

Emotional competence is what results and enhances our personal, relational and professional performance, and what ultimately helps us attain an overall increase in our quality of life. According to Daniel Goleman, Emotional Competence is a learned ability grounded in Emotional Intelligence. Our Emotional Intelligence influences our potential for learning the practical emotional competencies, and developing the emotional literacy necessary for Quality of Life, Life Satisfaction, and overall happiness. Such skills include the development of the following: Self/Social/Relational Awareness and Competence, and Self/Social/ Relational Management and Competence.

Emotional competencies determine how we manage ourselves. The higher you go in organizations, the more emotional intelligence (EI) matters. An emotional competence (EC) is a learned capability based on emotional intelligence that results in outstanding performance at work.

\section{Concept of Emotional Competence}

To achieve and maintain a feeling of adequacy, the individual has to acquire a few workable assumptions about the world, where need for competence emerges as most of the fundamental motive of life, because we survive through competence, grow through competence and actualize ourselves through competence Allport, 1961). The motivation towards competence is evident even in early playful and investigatory behavior of children, (White, 1959) which they seek in social realm and as close as any other need (closer than sexual) to sum up the growth of the personality. A varieties of factors such as intellectual, emotional and physical competencies play a part, (Coleman, 1970; Maslow, 1970) to acquire skill and knowledge and the individual begins to develop two important virtues- method and competence-in the congenial growth of personality.

Doing a thing is quite different from doing it well, where one can produce the type of effects one desires (White, 1959) may be termed as competence. It also refers to the mastering of abilities to do a task, sufficiency of means for living, easy circumstances or, in ethical sense, a right to take cognizance which specifies the process of observation, comprehension, explanation, exploration and manipulation of the experiences more objectively, (Allport, 1961) with the fullest use of an individuals normal capabilities. What turns doing anything into doing it well is essentially a display of competence and whenever this aspect of personality is related to emotions, it shall be deemed as emotional competence 
which happens to be efficiency that an individual acquire to deal with emotional situations effectively. The motivation to be emotionally competent is concerned more with product of abilities rather than their sheer exercise and works as a constructive force in shaping the individuals behavior, while inefficiencies may cause serious consequences in the dynamics of human behavior.

A sense of humor and the ability to both give and receive love are related to the sphere of emotions that are not provided as gifts but are to be developed by the individuals as their own characteristic pattern of emotional reactivity, which may contribute to or detract from mental and physical health and effectiveness of the individual.

How an individual handles his emotions, whether competently or incompetently, would be a question of emmence importance in explaining the growth of personality.

\section{Emotional Competencies:}

Emotional competence as an efficiency to deal effectively with several dissociable but related processes is a blending of five competencies, (Coleman, 1970). The different competencies may be understood as explained herewith.

\section{Adequate Depth of Feeling (ADF)}

Feeling in its broadest sense is any kind of process or experiencing, (English and English, 1958) characterized by predominance of "affect" and accessible emotions which lead to some kind of involvement to a great degree of the individual. A feeling of being confident of capable with all reality assumptions may be termed as adequate depth of feeling specifically associated with effective judgment and personality integration, which ensure vigorous participation in living.

\section{Adequate Expression and Control of Emotions (AECE)}

Generally the appropriate reaction to certain situation is not expressed adequately in emotional reactions and a mature person accepts his emotions as a part of himself, neither allows them to rule over him nor rejects them as aligned to his nature and is not at all worried because he accepts them and has an adequate control over them. Emotional competence requires both an adequate expression and their control, which may be, regarded as natural dynamic stability of an individual to express and control emotions spontaneously as demanded by the situation.

Adequate expression and control of emotions refer to a tendency marked by adequate emotional expressiveness based on fulsome expression and control of emotions. Any form of inadequate in either expression of control of emotions may lead to uncontrolled and disorganized emotionality.

\section{Ability to Function with Emotions (AFE)}

March, 2021. VOL.13. ISSUE NO. 1

https://hrdc.gujaratuniversity.ac.in/Publication

Page | 326 
It is sometimes difficult to carry out even routine work, when one finds himself face to face with a highly emotional situation. Emotional competence requires that the individual should develop a characteristic pattern of emotional reactivity which should not let him be influenced in his adequate mode of functioning that helps him in performing actions of daily routine properly.

\section{Ability to Cope with Problem Emotions (ACPE)}

Certain problem emotions play a destructive role and pose a potential damage to the life orientations of the individual's course of life. Therefore, emotional competence requires an understanding of the role of sensitivity and the detrimental effects of such emotions in the beginning and also a development of the ability to resist their harmful effects thereafter.

\section{Enhancement of Positive Emotions (EPE)}

The healthy growth of personality as well as adjustment with environment requires the presence of certain positive emotions like love, affection, joy etc. that shows a constructive influence in the dynamics of human behavior. Man is basically good and would like to deal with positive orientedness in most of the interactive situations of life. The growing vitality and a feeling of wholeness with a continuous capacity for intellectual and spiritual growth are the basic ingredients with an experience of positive emotions.

Previously known as encouragement of positive emotions, this competency has been renamed as enhancement of positive emotions as it felt, that one can only foster those emotions which one finds with in one's self.

Thus, enhancement of positive refers to the competency of the person to develop a predominance of positive emotions in the personality make-up of him to ensure a meaningful and fairly integrated life.

Six Dimensions of Emotional Competency: Emotional competencies- those learned capabilities based on emotional intelligence that result in outstanding performance - have six dimensions.

(1) Self-awareness: Self-awareness is based on an accurate self-assessment, on knowing your internal states, preferences, resources, intuitions, strengths and limitations. Selfconfidence suggests sureness about your self-worth and capabilities. Emotional awareness is recognizing your emotions and their effects. Effective leaders use their awareness to make good decisions and develop "it just feels right" intuition.

(2) Self-regulation: Self-control is about managing disruptive emotions and impulses. Trustworthiness is based on maintaining standards of honesty and integrity. Conscientiousness is taking responsibility for performance. Adaptability is your flexibility in handling change. 


\section{Ashwin Amraniya / Page 324-333}

And innovation is being comfortable with and open to novel ideas, approaches and new information.

(3) Motivation: We are motivated by emotional tendencies that guide or facilitate reaching goals. Our achievement drive motivates us to strive to improve or meet a standard of excellence. Commitment is about aligning with the group's goals. Initiative is our readiness to act on opportunities. Optimism is manifest in our persistence in pursuing goals. Emotion leads to the achievement of goals.

(4) Empathy suggests an awareness of others' feelings, needs and concerns. Understanding others is sensing their feelings and perspective. We develop a service orientation by anticipating, recognizing and meeting customers' needs. We best develop others by sensing what others need to develop. We best leverage diversity by cultivating opportunities through diverse people. We gain political awareness by rewarding the group's emotional currents and power relationships. As leaders, we show empathy by articulating unspoken feelings and listening to nurture the next generation.

Social skills are manifest by our ability to induce desirable responses in others. Influence is gained by wielding effective tactics for persuasion. Communication is sending clear and convincing messages. Leadership is about inspiring and guiding others, being a change catalyst by initiating or managing change and negotiating conflicts and disagreements. The leader's style is contagious.

(6) Group working skills are manifest in our adeptness at working with othersbuilding bonds and nurturing instrumental relationships. Collaboration and cooperation suggest working with others toward shared goals. Team capabilities are pursuing collective goals.

\section{Objective of the study:}

" To study the emotional competency of parented and orphanage adolescent in relation to different aspects of emotional competency.

Methodology:

Ho1: "There is no difference in emotional competency of orphanage female adolescent and the parented female adolescent".

Hola: There is no difference in adequate depth of feeling (ADF) of orphanage female adolescent and parented female adolescent.

Holb: There is no difference in adequate expression and control of emotions (AECE) of 
orphanage female adolescent and parented female adolescent.

Holc: There is no difference in ability function with emotions (AFE) of orphanage female adolescent and parented female adolescent.

Hold: There is no difference in ability to cope with problem emotions (ACPE) of orphanage female adolescent and parented female adolescent.

Hole: There is no difference in enhancement of positive emotions (EPE) of orphanage female adolescent and parented female adolescent.

Tools:

Scale of emotional competencies of Dr. H.C.Sharma and Dr. R.L.Bhardwaj, and its manual.

\section{Reliability and Validity:}

The reliability of the scale has been derived by employing two methods, viz., test-retest and split-half method. The obtained co-efficient of reliability may be enumerated as under:

\begin{tabular}{|l|c|c|c|c|c|c|}
\hline \multirow{3}{*}{\multicolumn{1}{|c|}{ Method }} & \multicolumn{5}{|c|}{ Emotional Competencies } & \multirow{2}{*}{ Total } \\
\cline { 2 - 6 } & $\begin{array}{c}\text { A } \\
\text { ADF }\end{array}$ & $\begin{array}{c}\text { B } \\
\text { AECE }\end{array}$ & $\begin{array}{c}\text { C } \\
\text { AFE }\end{array}$ & $\begin{array}{c}\text { D } \\
\text { ACPE }\end{array}$ & $\begin{array}{c}\text { E } \\
\text { EPE }\end{array}$ & \\
\hline $\begin{array}{l}\text { Test-Retest } \\
\text { (Interval 21-days) }\end{array}$ & .78 & .85 & .87 & .75 & .90 & .74 \\
\hline Split-half & .71 & .79 & .82 & .77 & .81 & .76 \\
\hline
\end{tabular}

The validity of this scale has been determined with $\mathrm{A}$ and $\mathrm{C}$ of 16 personality factor questionnaire and found to be .64 and .69 respectively.

\section{Sample:}

30 orphanages female from orphanage house and 30-parented female were taken for the study.

\section{Variables:}

(1). Independent variable:

Orphanages female from orphanage house and parented female is an independent variables of the study.

\section{(2). Dependent Variables:}


Towards Excellence: An Indexed, Refereed \& Peer Reviewed Journal of Higher Education / Dr. Ashwin Amraniya / Page 324-333

An emotional competency of parented female adolescent and orphanage female adolescent is the independent variable of the study.

\section{Design:}

The objective of this study is to compare the emotional competency of orphanage female and parented female adolescent, the revised scale of emotional competencies of Dr. H.C.Sharma and Dr. R.L.Bhardwaj will be taken.

A 30-orphanage female adolescent will be taken from the Orphanage House of Ahmedabad City and 30-adolescent parented female will be taken. And said sample will be tested for their emotional competencies. Further it will be scored and analyzed as per the manual of the test. The "t"test will be used for evaluate the data and hypothesis to conclude the problem.

\section{Results:}

Table-1:

Mean and SD of parented female adolescent

\begin{tabular}{|l|c|c|}
\hline \multicolumn{1}{|c|}{ Variables } & Mean & S.D. \\
\hline ADE & 53.63 & 7.56 \\
\hline AECE & 54.13 & 8.68 \\
\hline AFE & 54.93 & 7.51 \\
\hline ACPE & 55.93 & 8.30 \\
\hline EPE & 62.9 & 5.46 \\
\hline Z-Score & 281.4 & 27.09 \\
\hline T-Score & 61.96 & 8.49 \\
\hline
\end{tabular}

Table-2:

Mean and SD of Orphanage female adolescent

\begin{tabular}{|l|c|c|}
\hline \multicolumn{1}{|c|}{ Variables } & Mean & S.D. \\
\hline ADE & 54.86 & 9.51 \\
\hline AECE & 50.8 & 8.61 \\
\hline AFE & 53.1 & 8.44 \\
\hline ACPE & 54.16 & 8.09 \\
\hline EPE & 59.73 & 6.64 \\
\hline Z-Score & 270.76 & 31.16 \\
\hline T-Score & 58.13 & 9.39 \\
\hline
\end{tabular}

Table-3: 
Towards Excellence: An Indexed, Refereed \& Peer Reviewed Journal of Higher Education / Dr. Ashwin Amraniya / Page 324-333

"t" of parented female and orphanage female adolescent

\begin{tabular}{|l|c|c|}
\hline \multicolumn{1}{|c|}{ Variables } & t- value & Significant level \\
\hline ADE & 0.29 & NS \\
\hline AECE & 0.07 & NS \\
\hline AFE & 0.18 & NS \\
\hline ACPE & 0.20 & NS \\
\hline EPE & 0.02 & NS \\
\hline Z-Score & 0.08 & NS \\
\hline T-Score & 0.05 & NS \\
\hline
\end{tabular}

Discussion:

Present study is conducted to compare the parented and orphanage female adolescent in relation to their emotional competencies. The t-test found significant on ADF of parented female and orphanage female adolescent. Hence, the Hol (a) is accepted. This indicates that there is no difference in ADF of adolescent from general population and orphanage female adolescent. We can see it from the table-1; the mean of parented female adolescent for ADF is (53.63) where as the mean of orphanage adolescent is (54.86) and the " $\mathrm{t}$ " is 0.29 . So, the mean values of both the groups are almost same which indicates that there is no difference between the Adequate Depth of Feeling (ADF) in both the groups.

Table-1 shows the mean value of parented female adolescent for AECE is 54.13 and 50.8 is for the orphanage female adolescents. The "t" value is $(0.07)$ not significant; hence the Ho1 (b) is accepted which indicates that there is no difference in Adequate Expression and Control of Emotions between both the groups. Further the mean value of parented female adolescent for Ability to Function with Emotions (AFE) is 54.93 and 53.1 is for the orphanage female adolescents. The " $\mathrm{t}$ " value is (018) not significant; hence the Hol(c) is accepted which indicates that the ability of functioning with the emotions is same for both the groups.

The mean value of adolescent from general population for Ability to cope with Problem Emotions (ACPE) is 55.93 and 54.16 is for the orphanage female adolescents. The " $\mathrm{t}$ " value is $(0.20)$ not significant. So, ability of coping with problem emotions, same in both the groups; hence the Ho1 (d) is accepted.

The mean value of adolescent from parented female adolescent for Enhancement of Positive Emotions (EPE) is 62.9 and 59.73 is for the orphanage female adolescents. The "t" value is (0.02) not significant. So, enhancement of positive emotions, same in both the groups; hence the Ho1 (e) is accepted.

The $\mathrm{t}$-scores showing the total score of all above-mentioned emotional competencies is 61.96 for the parented female adolescent and 8.13 is for orphanage female adolescents. The " $t$ " value of both the March, 2021. VOL.13. ISSUE NO. $1 \quad$ https://hrdc.gujaratuniversity.ac.in/Publication 
groups is 0.05 , which is not significant; hence the Hol is accepted. This indicates that there is no difference in emotional competencies of both the groups.

It was expected that the emotional competencies of parented female adolescent would be higher than the female adolescent of orphanage house. But the result of this study is absolutely surprising, the level of emotional competencies of both the groups found same. The reason for this results could be the enough care is taking by care takers of orphanage house, not only government but our society is also providing many facilities for such orphanage house. These lead them towards maintain their level of emotional competencies as parented female adolescent.

\section{Conclusion:}

There was no significant difference of emotional competencies found between the parented female adolescent and orphanage female adolescents. 


\section{Reference}

Allport, G.W. (1961) patterns and Growth in Personality. New York:

HoltRhinehart and Winston.

(2) Goleman, Daniel, Emotional Competence, Executive Excellence; April 1999; 16, 4; ABI/INFORM Global, Pg.-19.

(3) Bhardwaj, R. L. (1994) Development of emotional competencies measures. Indian Journal of Psychology \& Education, 69, 133-138.

(4) Bhardwaj, R.L. \& Sharma H.C. (1994), The scale of Emotional Competencies (Revised Scale.

(5) Coleman, J. C. (1970) Abnormal Psychology and Modern Life: Bombay: D.B.Taraporevala Sons \& Co. Pvt. Ltd.

(6) English H.B. \& English A.C. (1958) A Comprehensive Distionary of Psychology and Psychoanalytical Terms. New York: LongmansGreen.

(7) Maslow, A.H. (1970) Motivation and Personality (2 ${ }^{\text {nd }}$ ed.) New York: Harper \& Row.

(8) White, R.W. (1959) Motivation Reconsidered: The concept fof Competence. Psychological Review, 66, 297-833.

\section{Dr. Ashwin Savjibhai Amraniya Assistant Professor C.U. Shah Arts College, Lal Darwaja Ahmedabad}

